\title{
Effect of anodizing voltage and pore widening time on the effective refractive index of anodic titanium oxide
}

\author{
N. A. Sapoletova ${ }^{1}$, S. E. Kushnir ${ }^{1,2 *}$, K. S. Napolskii ${ }^{1,2}$ \\ ${ }^{1}$ Department of Chemistry, Lomonosov Moscow State University, 119991, Moscow, Russia \\ ${ }^{2}$ Department of Materials Science, Lomonosov Moscow State University, 119991, Moscow, Russia \\ *kushnir@elch.chem.msu.ru
}

PACS 42.25.Gy, 82.45.Aa, 82.45.Cc

DOI 10.17586/2220-8054-2019-10-2-154-157

\begin{abstract}
The unique optical properties of porous anodic titanium oxide (ATO) make it a promising material for solar energy conversion, sensorics, and opto-electronics. The optical path length and effective refractive index $\left(n_{\text {eff }}\right)$ of ATO can be tuned by chemical etching of pore walls. However, precise control of these optical parameters is still challenging due to the lack of data on the effect of pore widening time on the $n_{\text {eff }}$. Here, a detailed study of the influence of anodizing voltage and pore widening time on the $n_{\text {eff }}$ of the ATO films was performed. Analysis of reflectance spectra of ATO synthesized at $35-50 \mathrm{~V}$ shows that pore widening in $3 \mathrm{wt} . \% \mathrm{H}_{2} \mathrm{O}_{2}$ aqueous solution allows one to control the $n_{\text {eff }}$ at values ranging from 1.54 to 1.84 . The data required for the prediction of the thickness, $n_{\text {eff }}$, and optical path length of the ATO films from anodizing and etching conditions are obtained.
\end{abstract}

Keywords: anodic titanium oxide, anodization, porous materials, film, refractive index, optical materials and properties.

Received: 5 April 2019

Revised: 15 April 2019

\section{Introduction}

Anodizing is one of the more promising methods for the production of porous $\mathrm{TiO}_{2}$ films at room temperature [1]. Porous anodic titanium oxide (ATO) films demonstrate high efficiency in water photoelectrolysis [2], photocatalysis [3,4], gas sensing [5], and can be used as carriers for controlled drug release [6-8]. In addition, ATO films have potential for application in dye-sensitized solar cells [9], refractive index sensors [10,11], smart color windows, and electronic displays [12] owing to a high refractive index $\left(n_{\mathrm{TiO}_{2}}=2.6\right.$ at $\lambda=600 \mathrm{~nm}$ [13]) and semiconductor properties of titanium oxide.

Optical path length of ATO films, the product of the film thickness and refractive index, is one of the key parameters that has great importance for optical applications. The thickness of ATO is directly proportional to charge density consumed during anodizing [14,15], whereas control of the refractive index of ATO more challenging. Taking into account a small diameter of the pores in ATO films, which is much lower than the wavelength of visible light, the effective refractive index $\left(n_{\mathrm{eff}}\right)$ of ATO is a function of film porosity within a framework of the effective medium model. It is worth noting that the porosity and the $n_{\text {eff }}$ values for anodic oxides change during the anodizing process due to chemical etching of the pore walls [16]. To the best of our knowledge, there are no systematic data on the $n_{\text {eff }}$ of ATO as a function of anodizing voltage and the duration of chemical etching.

Here, we study the dependence of the thickness-to-charge density ratio and the $n_{\text {eff }}$ of ATO films on anodizing voltage. Special attention is paid to the variation of the $n_{\text {eff }}$ caused by chemical etching of pore walls in the anodizing electrolyte and aqueous $\mathrm{H}_{2} \mathrm{O}_{2}$ solution.

\section{Materials and methods}

Prior to anodizing, titanium foils $(0.15 \mathrm{~mm}$ thick, $99.6 \%$ purity $)$ were electrochemically polished in a mixture of 99.5 wt. \% acetic acid and 65 wt. \% perchloric acid with a volume ratio of 9:1. Electrochemical polishing was performed over 4 min under square-wave applied voltage ( $40 \mathrm{~V}$ for $10 \mathrm{~s}$ and $60 \mathrm{~V}$ for $10 \mathrm{~s})$ at a temperature below $25{ }^{\circ} \mathrm{C}$ as described elsewhere [15].

To prepare porous anodic titanium oxide films, Ti was anodized at a constant voltage between $30-60 \mathrm{~V}$ in an ethylene glycol electrolyte containing 0.3 wt. $\% \mathrm{NH}_{4} \mathrm{~F}, 0.66$ wt. $\% \mathrm{CH}_{3} \mathrm{COONa}$, and 2 wt. $\% \mathrm{H}_{2} \mathrm{O}$ at $30{ }^{\circ} \mathrm{C}$. The electrolyte solution was prepared by adding aqueous $\mathrm{NH}_{4} \mathrm{~F}$ to sodium acetate dissolved in ethylene glycol. The electrolyte was stirred at 480 RPM using an overhead stirrer. Experiments were performed in a two-electrode electrochemical cell with the distance of $2 \mathrm{~cm}$ between Ti electrodes. The anodized area and the total charge density consumed during anodizing of each sample was $1.13 \mathrm{~cm}^{2}$ and $3.36 \mathrm{C} \cdot \mathrm{cm}^{-2}$, respectively. To study pore 
widening effect on the $n_{\text {eff }}$ of the ATO in electrolyte, some of the prepared films were stored in electrolyte solution for $2-6$ hours after anodizing. Finally, the ATO films were washed with ethanol and then air-dried. Some as-synthesized ATO films were aged in 3 wt. $\% \mathrm{H}_{2} \mathrm{O}_{2}$ aqueous solution for 7.5 - 30 minutes under stirring.

Morphological characterization of the ATO films was performed by scanning electron microscopy (SEM) using LEO Supra 50 VP instrument. Perkin Elmer Lambda 950 spectrophotometer was used to record the reflectance spectra at incident angles of $8,30,45,60$, and $65^{\circ}$ in a wavelength range of $650-890 \mathrm{~nm}$.

\section{Results and discussion}

Optical reflectance spectra of the ATO films prepared at different anodizing voltages $(U)$ are shown in Fig. 1a. In the case of the ATO obtained at $U=35-50 \mathrm{~V}$, intense Fabry-Pérot oscillations of the reflectivity can be clearly seen in the spectra, resulting in high thickness uniformity for these samples at least across the irradiated area $\left(4 \times 4 \mathrm{~mm}^{2}\right)$. The Fabry-Pérot oscillations in the spectra of the samples, prepared at anodizing voltages outside the $35-50 \mathrm{~V}$ range, are weak or completely lacking, manifesting non-uniform thickness. Thus, the range of $35-50 \mathrm{~V}$ was chosen to study the dependence of the $n_{\mathrm{eff}}$ of the ATO films on the pore widening duration.
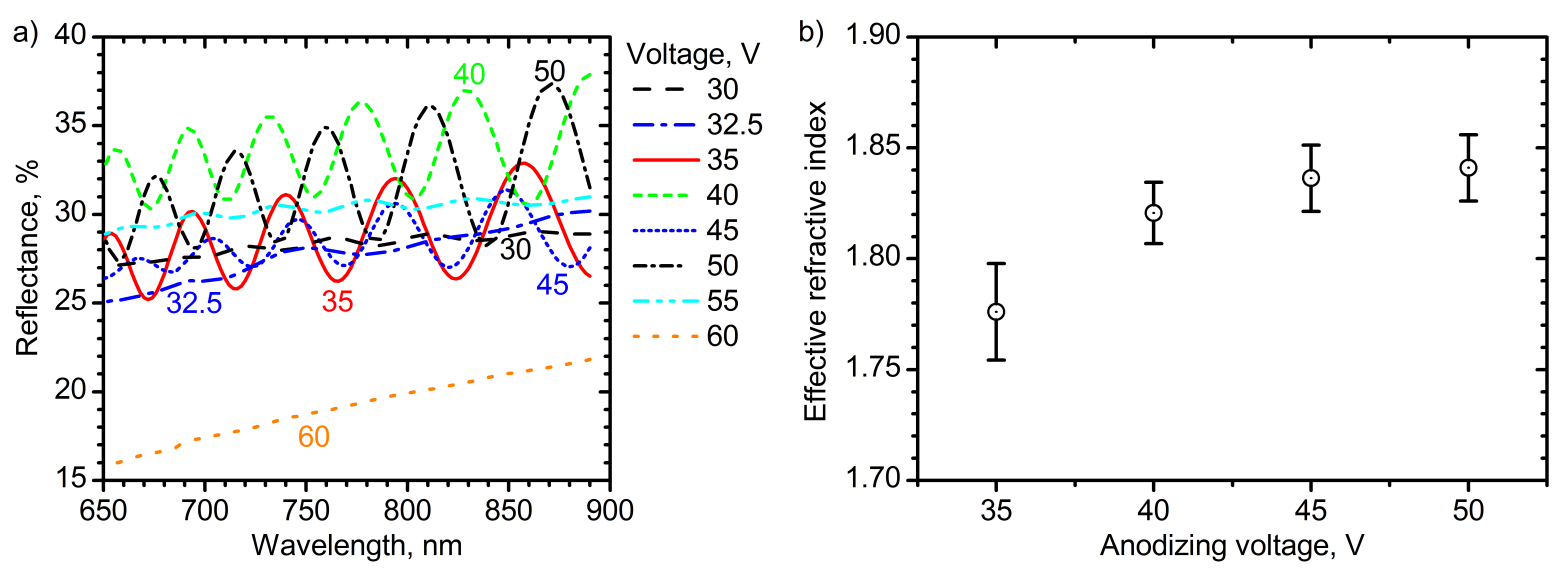

FIG. 1. Optical properties of ATO films prepared at various anodizing voltages. (a) Reflectance spectra recorded at incident angle of $8^{\circ}$. (b) The effective refractive index at $700 \mathrm{~nm}$ as a function of anodizing voltage

The positions of Fabry-Pérot oscillations in the spectra recorded at different incident angles were used for calculating the $n_{\text {eff }}$ and sample thickness $(h)$ using a protocol described previously [17]. The $n_{\text {eff }}$ increases from 1.78 to 1.84 with growth of anodizing voltage from 35 to $50 \mathrm{~V}$ (Fig. 1 b). Thickness-to-charge density ratio $(h / q)$ lies in the range of $0.88-1.00 \mu \mathrm{m} \cdot \mathrm{cm}^{2} \cdot \mathrm{C}^{-1}$.

Typical SEM images of the ATO are shown in Fig. 2 on the example of the sample prepared at 35 V. ATO film consists of vertically aligned nanotubes contacting each other. The average distance between the centers of neighboring nanotubes $\left(D_{\text {int }}\right)$ increases linearly from 79 to $111 \mathrm{~nm}$ with an increase in the anodizing voltage from 35 to $50 \mathrm{~V}$; the proportionality constant $D_{\text {int }} / U$ is $2.23 \pm 0.03 \mathrm{~nm} \mathrm{~V}{ }^{-1}$, that is inside the range of corresponding value observed earlier for ethylene glycol based electrolytes $(1.8-3.0)$ [14]. According to SEM data, the thickness of the samples prepared at $U=35-50 \mathrm{~V}$ is in the range of $2.9-3.2 \mu \mathrm{m}$, and thickness-to-charge density ratio lies in the range of $0.86-0.95 \mu \mathrm{m} \cdot \mathrm{cm}^{2} \cdot \mathrm{C}^{-1}$. It is worth noting that these values are in good agreement with spectral data.

The dependence of the effective refractive index of ATO films on the duration of chemical etching is shown in Fig. 3. Chemical etching of nanotube walls in $\mathrm{F}^{-}$-containing electrolyte solution leads to the growth of the porosity of the ATO, resulting in a decrease in the $n_{\text {eff }}$ (Fig. 3a). The rate of pore widening in electrolyte solution is slow enough: change of the $n_{\text {eff }}$ after several hours of etching is lower than 0.11 independently of anodizing voltage. A stronger (up to 0.28 ) decrease in the $n_{\text {eff }}$ is observed in the aqueous $\mathrm{H}_{2} \mathrm{O}_{2}$ solution (Fig. 3b). The rate of pore widening is substantially faster only during the first 15 minutes of etching. Further etching leads to a minor change in the $n_{\text {eff }}$ followed by the detaching of ATO film after $30 \mathrm{~min}$. Pore widening in $\mathrm{H}_{2} \mathrm{O}_{2}$ solution increases the difference between the $n_{\text {eff }}$ of the layers obtained at 35 and $50 \mathrm{~V}\left(\Delta n_{\text {eff }}\right)$ from 0.06 to 0.14 . The trend of the $\Delta n_{\text {eff }}$ increase during pore widening is in good agreement with one reported for the anodic alumina films prepared in oxalic [18] and sulfuric acid electrolytes [16]. Most likely, the decrease in etching rate (decreasing of the $n_{\text {eff }}$ ) after $7.5 \mathrm{~min}$ in $\mathrm{H}_{2} \mathrm{O}_{2}$ is caused by layered structure of ATO pore walls. The inner layer, contacting with 

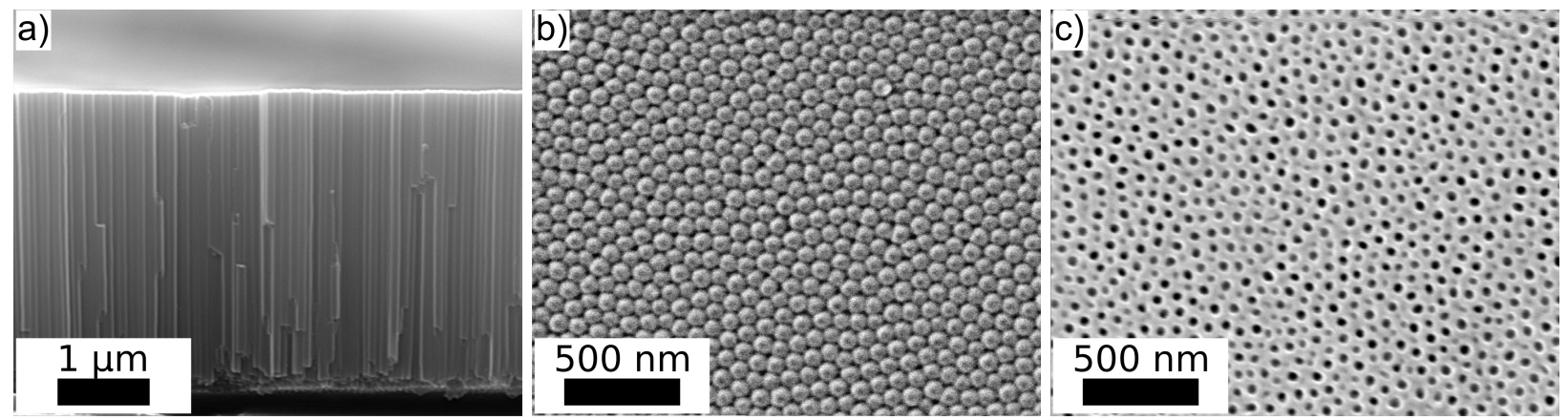

FIG. 2. SEM images of the ATO film prepared at $U=35 \mathrm{~V}$ : cross section (a), bottom (b) and top view (c)
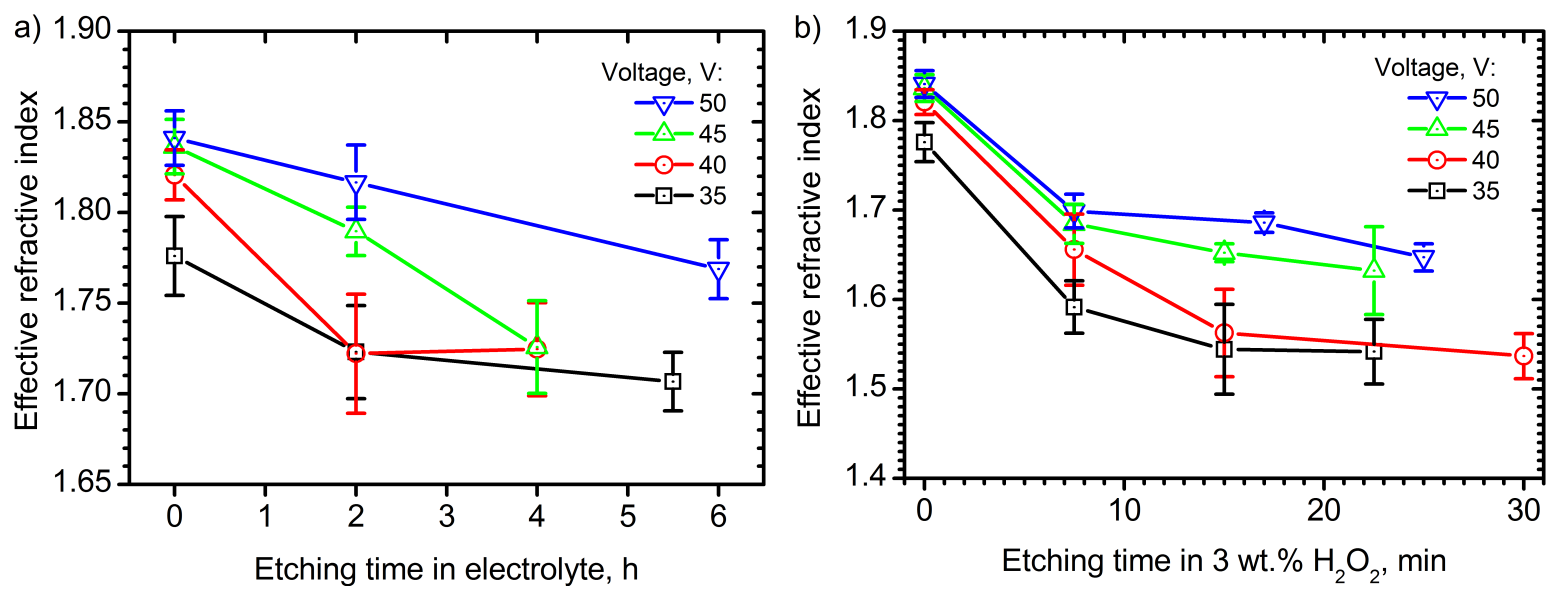

FIG. 3. Dependence of the effective refractive index at $700 \mathrm{~nm}$ on pore widening time for the ATO films prepared at $35-50 \mathrm{~V}$ : in the electrolyte (a) and in the 3 wt. $\% \mathrm{H}_{2} \mathrm{O}_{2}$ aqueous solution (b)

electrolyte during anodizing, contains more impurities from electrolyte, that makes it less stable than the deeper layer consisting mainly of titania [19]. Obtained quantitative data on thickness and the $n_{\text {eff }}$ of ATO will be in demand for the design of materials for antireflection coatings, memristive elements [20], photonic crystals [21], and solar cells.

\section{Conclusions}

High uniformity for the ATO film thickness was observed for the samples obtained in ethylene glycol electrolyte (0.3 wt. $\% \mathrm{NH}_{4} \mathrm{~F}, 0.66$ wt. $\% \mathrm{CH}_{3} \mathrm{COONa}, 2$ wt. $\% \mathrm{H}_{2} \mathrm{O}$ ) at anodizing voltages ranging from 35 to $50 \mathrm{~V}$. The values of film thickness-to-charge density ratio vary from 0.86 to $1.00 \mu \mathrm{m} \cdot \mathrm{cm}^{2} \cdot \mathrm{C}^{-1}$ according to analysis of the reflectance spectra and SEM images. The $n_{\mathrm{eff}}$ at $700 \mathrm{~nm}$ of the as-prepared ATO films is in the range of $1.78-$ 1.84, which is higher than in the case of anodic alumina and bulk $\mathrm{Al}_{2} \mathrm{O}_{3}$. Pore widening in $\mathrm{H}_{2} \mathrm{O}_{2}$ solution allows one to achieve the lower bound of the $n_{\text {eff }}$ of 1.54 and to increase the difference between the $n_{\text {eff }}$ of the layers obtained at 35 and $50 \mathrm{~V}$ from 0.06 to 0.14 . Chemical etching in aqueous $\mathrm{H}_{2} \mathrm{O}_{2}$ solution is an effective method for tuning the porosity of ATO films, saving their planarity and uniformity.

\section{Acknowledgements}

This work is supported by the Russian Science Foundation under grant No. 17-73-10471. Some experiments were carried out using the scientific equipment purchased by M. V. Lomonosov Moscow State University Program of Development.

\section{References}

[1] Regonini D., Bowen C.R., Jaroenworaluck A., Stevens R. A review of growth mechanism, structure and crystallinity of anodized TiO 2 nanotubes. Materials Science and Engineering: R: Reports, 2013, 74 (12), P. 377-406. 
[2] Shankar K., Mor G.K., et al. Highly-ordered $\mathrm{TiO}_{2}$ nanotube arrays up to $220 \mu \mathrm{m}$ in length: use in water photoelectrolysis and dyesensitized solar cells. Nanotechnology, 2007, 18 (6), 065707.

[3] Varghese O.K., Paulose M., LaTempa T.J., Grimes C.A. High-rate solar photocatalytic conversion of $\mathrm{CO}_{2}$ and water vapor to hydrocarbon fuels. Nano Letters, 2009, 9 (2), P. 731-737.

[4] Arfanis M.K., Adamou P., et al. Photocatalytic degradation of salicylic acid and caffeine emerging contaminants using titania nanotubes. Chemical Engineering Journal, 2017, 310, P. 525-536.

[5] Varghese O.K., Gong D., et al. Hydrogen sensing using titania nanotubes. Sensors and Actuators B: Chemical, 2003 , 93 (1), P. $338-344$.

[6] Song Y.-Y., Schmidt-Stein F., Bauer S., Schmuki P. Amphiphilic $\mathrm{TiO}_{2}$ nanotube arrays: an actively controllable drug delivery system. Journal of the American Chemical Society, 2009, 131 (12), P. 4230-4232.

[7] Gulati K., Kant K., Findlay D., Losic D. Periodically tailored titania nanotubes for enhanced drug loading and releasing performances. Journal of Materials Chemistry B, 2015, 3 (12), P. 2553-2559.

[8] Wang Q., Huang J.-Y., et al. Recent advances on smart $\mathrm{TiO}_{2}$ nanotube platforms for sustainable drug delivery applications. International Journal of Nanomedicine, 2016, 12, P. 151-165.

[9] Kim D., Ghicov A., Albu S.P., Schmuki P. Bamboo-type $\mathrm{TiO}_{2}$ nanotubes: improved conversion efficiency in dye-sensitized solar cells. Journal of the American Chemical Society, 2008, 130 (49), P. 16454-16455.

[10] Wang G., Wang J., An Y., Wang C. Anodization fabrication of 3D $\mathrm{TiO}_{2}$ photonic crystals and their application for chemical sensors. Superlattices and Microstructures, 2016, 100, P. 290-295.

[11] Kim W.-T., Choi W.-Y. Fabrication of $\mathrm{TiO}_{2}$ photonic crystal by anodic oxidation and their optical sensing properties. Sensors and Actuators A: Physical, 2017, 260, P. 178-184.

[12] Zheng L., Cheng H., et al. Porous $\mathrm{TiO}_{2}$ photonic band gap materials by anodization. The Journal of Physical Chemistry C, 2012, 116 (9), P. 5509-5515.

[13] DeVore J.R. Refractive indices of rutile and sphalerite. JOSA, 1951, 41 (6), P. 416-419.

[14] Cortes F.J.Q., Arias-Monje P.J., Phillips J., Zea H. Empirical kinetics for the growth of titania nanotube arrays by potentiostatic anodization in ethylene glycol. Materials \& Design, 2016, 96, P. 80-89.

[15] Sapoletova N.A., Kushnir S.E., Napolskii K.S. Anodic titanium oxide photonic crystals prepared by novel cyclic anodizing with voltage versus charge modulation. Electrochemistry Communications, 2018, 91, P. 5-9.

[16] Kushnir S.E., Pchelyakova T.Yu., Napolskii K.S. Anodizing with voltage versus optical path length modulation: a new tool for the preparation of photonic structures. Journal of Materials Chemistry C, 2018, 6 (45), P. 12192-12199.

[17] Kushnir S.E., Napolskii K.S. Thickness-dependent iridescence of one-dimensional photonic crystals based on anodic alumina. Materials \& Design, 2018, 144, P. 140-150.

[18] Rahman M.M., Garcia-Caurel E., et al. Effect of the anodization voltage on the pore-widening rate of nanoporous anodic alumina. Nanoscale Research Letters, 2012, 7 (1), 474.

[19] Dronov A., Gavrilin I., et al. Investigation of anodic $\mathrm{TiO}_{2}$ nanotube composition with high spatial resolution AES and ToF SIMS. Applied Surface Science, 2018, 434, P. 148-154.

[20] Morozova P.A., Petukhov D.I. Preparation of $\mathrm{Au} / \mathrm{TiO}_{2} / \mathrm{Ti}$ memristive elements via anodic oxidation. Nanosystems: Physics, Chemistry, Mathematics, 2017, 8 (6), P. 823-829.

[21] Ermolaev G.A., Kushnir S.E., Sapoletova N.A., Napolskii K.S. Titania photonic crystals with precise photonic band gap position via anodizing with voltage versus optical path length modulation. Nanomaterials, 2019, 9 (4), P. 651. 